\title{
Assessing the Food Security of Vulnerable Agricultural Households to Climate Change in the Council of Tokombéré, Far North Région of Cameroon: An Analysis Focused on the FCS, HDDS and CSI
}

\author{
Moluh Njoya Hamza ${ }^{*}$, Fon Dorothy Engwali, Soh Wenda Boris Dinictri \\ Faculty of Agronomy and Agricultural Sciences, University of Dschang, Dschang, Cameroon \\ Email address \\ hamzanjoya@gmail.com (M. N. Hamza), dengwali@yahoo.fr (F. D. Engwali), bswenda@yahoo.com (S. W. B. Dinictri) \\ ${ }^{*}$ Corresponding author
}

To cite this article:

Moluh Njoya Hamza, Fon Dorothy Engwali, Soh Wenda Boris Dinictri. Assessing the Food Security of Vulnerable Agricultural Households to Climate Change in the Council of Tokombéré, Far North Région of Cameroon: An Analysis Focused on the FCS, HDDS and CSI. International Journal of Agricultural Economics. Vol. 4, No. 1, 2019, pp. 19-25. doi: 10.11648/j.ijae.20190401.13

Received: December 18, 2018; Accepted: January 10, 2019; Published: January 28, 2019

\begin{abstract}
This article evaluates the food security of agricultural producers vulnerable to climate change in the Tokomberé council through the analysis of food consumption scores, dietary diversity score and the analysis of the index of adaptability for the food. The data were collected using a questionnaire administered to 160 farm households that were selected by the stratified random sampling technique. Analysis of the data collected reveals that $82.5 \%$ of households are headed by men and $17.5 \%$ by women with very low level of education ( $55 \%$ have not been to school and only $45 \%$ have a primary level) and have an age between 50 and 75 (70.6\%). The average SCA is 37.06 (acceptable), so $36.88 \%$ of households have an acceptable SCA of which in food security and $56.88 \%$ have a SCA limit of which moderately food insecure and $6.25 \%$ have a SCA poor whose food insecurity is severe. The average SDAM is 3.58 (acceptable) with a minimum SDAM of 2 and a maximum SDAM of 9. With SDAM; $90 \%$ and $79.12 \%$ of households are severely food insecure and moderately food insecure respectively. SDAM analyzes also show $75.6 \%, 20 \%$ and $4.4 \%$ of households with the lowest, average and highest dietary diversity respectively. The average CSI is 21.1 with a CSI min of 11 and a CSI max of 30.
\end{abstract}

Keywords: Food Security, Agricultural Household, Vulnerability, Climate Change, Tokombéré

\section{Introduction}

Global climate change and its many impacts on people's lives affect the entire planet, but are a major challenge for developing countries. Populations in these countries are highly dependent on natural resources and often have relatively limited adaptive capacity [1]. As a result, these countries are often among the most seriously affected by climate change [2]. In Cameroon, as in many other countries in sub-Saharan Africa, the effects of climate change are more palpable than ever. Climate change negatively impacts food security. As the effects of climate change become more pronounced, it will become increasingly difficult to achieve food security and continue to plunge people into food insecurity. Its effects on food production and distribution are likely to increase poverty and inequality, with implications for livelihoods and nutrition [3]. The region of the Far North Cameroon, in addition to its aridity, is currently characterized by massive movements of refugees and displaced people following the acts of violence perpetrated by the Islamic State of Africa. It is presented as one of the most densely populated areas, and also the poorest in the country. Indeed, the United Nations [4] states that $15.4 \%$ of Cameroon's population suffers from hunger and that about $31.7 \%$ of children under five are malnourished. The Far North Region is particularly the most affected by food insecurity with $35.5 \%$, followed by the Adamawa Region with $18.7 \%$ and the Northern Region with $10 \%$ [5]. This instability, which amplifies the pre-existing problems of chronic malnutrition and food insecurity, is leading to increasing population 
movements. Millions of people are undernourished because they do not have access to enough food. They live mainly in rural areas of the tropics and their vulnerability is increased by socio-economic, demographic and political trends limiting their ability to adapt to climate change [6].

\section{Methodology}

\subsection{Presentation of the Study Area}

The study was conducted in the Far North Cameroon region, especially in Tokombéré commune. It differs from other regions of Cameroon by its geographical position, its demography and its economy. Tokombéré has 35 villages. It is between Latitude $10^{\circ} 52^{\prime}$ North and Longitude $14^{\circ} 09^{\prime}$ East in the Mayo Sava Department. Tokombéré is characterized by a Sudano-Sahelian type dry tropical climate with a long dry season of about eight (8) months (October-May) and a short rainy season spread over four (4) months (June to September). . This climate is characterized by recurring pockets of drought and annual average rainfall decreasing over time. Annual rainfall varies from 600 to $1,100 \mathrm{~mm}$ with an average of $700 \mathrm{~mm}$. The minimum temperatures are around $20^{\circ} \mathrm{C}$ with a maximum of $35^{\circ} \mathrm{C}$ and an annual average of $30^{\circ} \mathrm{C}$. The period from July to September is the mildest and corresponds to the rainy season. However, the months of March-April-May and sometimes June have the highest temperatures up to $45^{\circ} \mathrm{C}$, this part of the year is the one that is the worst because of the difficulties associated in particular with the heat monitoring of lack of water in most villages and neighbourhoods of Tokombéré city for humans and animals. The study was conducted during this period. The population is estimated at 91,256 inhabitants covering an area of 552 $\mathrm{km}^{2}$.

\subsection{Sampling Technique and Sample Size}

By consultation of the Tokombéré communal development plan and with the help of ACF Maroua's food security and livelihoods team, 4 out of 6 cantons were selected. These are the township of Mada, Sérawa Makalingai and Bzagamtagna. Two villages from each of the selected cantons were randomly selected, making a total of 8 out of 35 villages in the municipality selected. Thus the following villages were selected: Serawa center, Dalazulgo, Bzagamtagna, Kayamgali, Mounduvaya, Makalingai center, Gozogol and Jileng. 20 households in each of the 8 villages were randomly selected, a total of 160 households surveyed.

\subsection{Data Analysis}

The data collected on food security were analyzed using the Statistical Package for Social Sciences (SPSS) Version 20 (SPSS 2014) and Microsoft Excel 2013 software. The food consumption score (FCS), the dietary diversity score (HDDS) and the Adaptation Strategy Index (CSI) were used to assess food security, the Vulnerability and Climate Change Adaptability Analysis (CVCA) was conducted to identify food security mechanisms adapted by farming households. The FCS, the HDDS and the CSI were determined using the following formulas.

\subsubsection{Household Food Consumption Score (FCS)}

The FCS is based on a 7-day reference. That is to say, a 7day recall on the eight groups (cereals and tubers, legumes, dairy products, fruits, vegetables, meat and fish, sugars, oils) of foods (diversity) and the frequency of consumption. It is determined by the following formula.

$$
F C S=\sum_{j=1}^{n} a_{j} x_{j}
$$

With:

$\mathrm{j}=$ food group

$\mathrm{X}_{\mathrm{j}}=$ Number of days of consumption relative to each food group ( $\leq 7$ days) $a_{j}=$ weight coefficient of group $\mathrm{j}$ or Weight attributed to food group $\mathrm{j}, \mathrm{n}=$ number of food groups that equals 8 .

\subsubsection{The Household Dietary Diversity Score (HDDS)}

Unlike the FCS, the HDDS is based on a one-day reference. That is, a 24-hour recall on twelve food groups (Cereals, Fish and Seafood, Roots and Tubers, Pulses / Legumes / Nuts, Vegetables, Milk and Dairy Products, Fruits, Oil / fats, meat, poultry, offal, sugar / honey, eggs and miscellaneous). For the HDDS (between 0 and 12) which is the total number of food groups consumed by household members, we have the following formula

$$
\operatorname{HDDS}(0-12)=\mathrm{A}+\mathrm{B}+\mathrm{C}+\mathrm{D}+\mathrm{E}+\mathrm{F}+\mathrm{G}+\mathrm{H}+\mathrm{I}+\mathrm{J}+\mathrm{K}+\mathrm{L}
$$

From $\mathrm{A}$ to $\mathrm{L}=$ food groups consumed by household members. The values for A to $L$ are either "0" or "1."

Second, the average HDDS indicator is calculated for the sample population following the formula.

$$
\text { average HDDS }=\frac{\text { Sum (HDDS) }}{\text { Total number of households }}
$$

\subsubsection{Coping Strategy Index (CSI)}

For the coping strategy Index, just like the FCS, the CSI is determined in the same way as the FCS, but with the only difference that the food groups in the SCA formula are the groups of strategies in the CSI determination. The mathematical representation is as follows.

$$
C S I=\sum_{j=1}^{n} \text { strategies }_{j}\left(A_{j} B_{j}\right)
$$

With

$\mathrm{A}_{\mathrm{j}}=$ frequency and $\mathrm{B}_{\mathrm{j}}=$ universal weight of severity of strategies

First we will determine the CSI for each household and then sum up to have the total CSI.

\section{Results and Discussions}

The food security assessment was done by analyzing the three specific indicators of food security such as the 
household food consumption score (FCS), the household dietary diversity scores (HDDS) and the index; Adaptation Strategies for Food (CSI).

\subsection{Evaluation of Food Security by Determining of Food Consumption Scores (FCS)}

The analysis of food consumption was based on a 7-day recall on the different food groups consumed by households. It should be noted that the more diversified the diet (number of food groups eaten high) and the high frequency (number of times the food groups are consumed over a week), the better the quality of the diet. The following figure shows the average consumption frequencies for each food group.

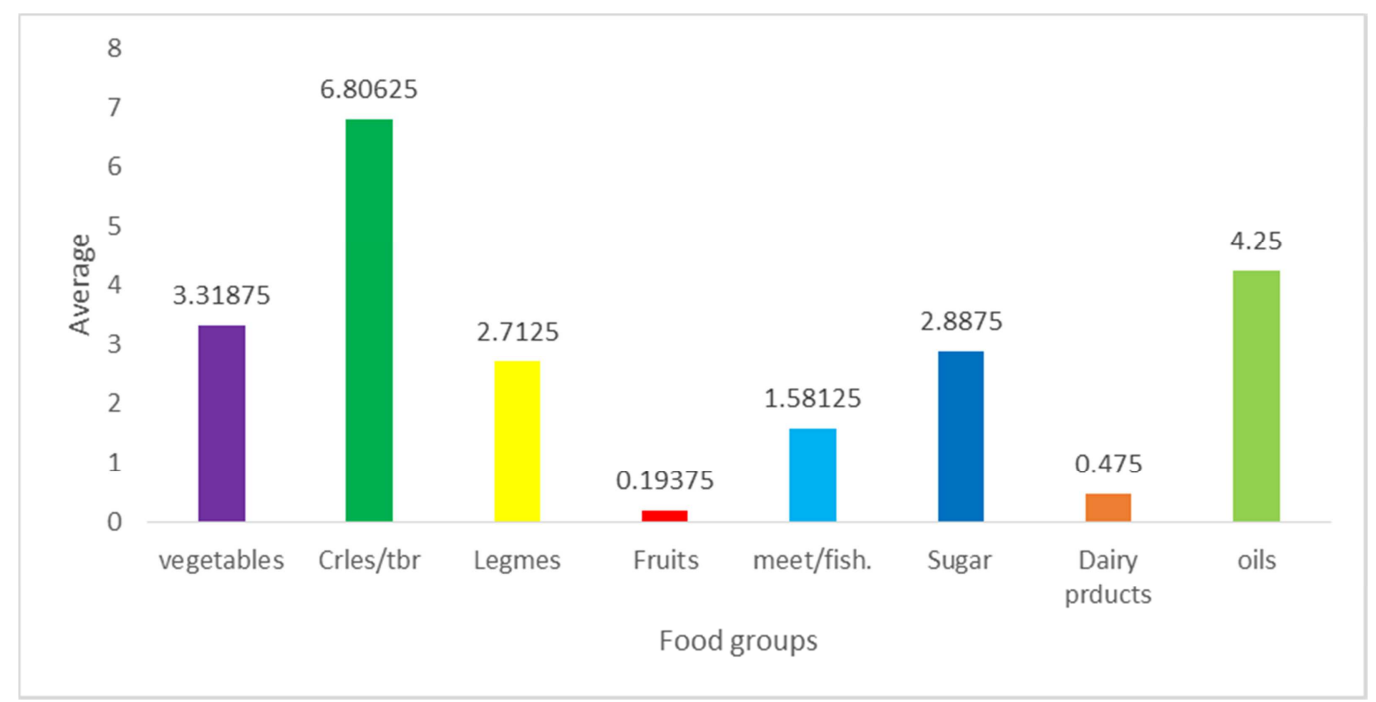

Figure 1. The average consumption frequencies of each food group.

The average number of daily meals for children and adults is two for the survey period, which is not good because households reduce the number of daily meals to cope with the lack of food. These results are different from those obtained by the World Food Program [7] where the average meal per household per day in Cameroon was 2.5.

Analysis of the data collected from the food consumption questionnaire reveals that the households surveyed consume cereals almost every day (6.81 days / week), as they constitute staple foods. This is not the case for the oil with an average frequency of 4.25 days / week (Table 1).

The least consumed food groups are those of fruits and dairy products whose average frequency does not even reach 1 day / week ( 0.194 and 0.475 days / week for the fruit and dairy groups respectively). $47.5 \%$ of the surveyed households acknowledged that they had eaten dairy products at least once 7 days before the survey. The rest (52.5\%) did not even consume these products 7 days before the survey.

This low consumption could be explained by the lack of awareness of the importance of the consumption of dairy products in children in addition to the lack of financial means and the extreme weather conditions to which the population is subject and which contribute to the high price of fruits. Also meat and fish are less eaten, with an average frequency of 1.58 days / week (Table 1). These weekly frequencies are very similar to those found by Dibango [8] in Balmayo and contrary to those obtained by the World Food Program [9] in the central Cameroon region. These frequencies are summarized in Table 1.

Table 1. Weekly frequencies of different food groups compared to those of Yaounde.

\begin{tabular}{|c|c|c|c|c|c|}
\hline Consumed food groups & $\begin{array}{l}\text { Minimum frequency } \\
\text { (in days / week) }\end{array}$ & $\begin{array}{l}\text { Maximum } \\
\text { Frequency (in } \\
\text { days / week) }\end{array}$ & $\begin{array}{l}\text { Average Frequency } \\
\text { (in days / week) }\end{array}$ & $\begin{array}{l}\text { Standard } \\
\text { deviation }\end{array}$ & $\begin{array}{l}\text { Average frequency (in } \\
\text { days / week) of the } \\
\text { Central Region (WFP) }\end{array}$ \\
\hline Vegetables and leaves & 2 & 7 & 3,06 & 1,31 & 4,5 \\
\hline Cereals and tubers & 6 & 7 & 6,79 & 0,4 & 6,5 \\
\hline legumes & 0 & 1 & 0,49 & 0,5 & 0,5 \\
\hline Fruits & 0 & 2 & 0,19 & 0,59 & 6,2 \\
\hline Dairy products & 0 & 1 & 0,47 & 0 & 0,3 \\
\hline Meat and fish & 1 & 2 & 1,58 & 1,04 & 2,6 \\
\hline Sugar products & 2 & 4 & 3 & 1,05 & 1,2 \\
\hline Oils & 4 & 5 & 4,5 & 0,94 & 5,2 \\
\hline
\end{tabular}

The food consumption score (FCS) is a composite indicator, which reflects both the dietary diversity, the frequency and the relative nutritional intake of each product and group of foods consumed by a household. The method of calculating the food consumption score and the weight assigned to each food group are found in the methodology. 
Table 2. Household food consumption score.

\begin{tabular}{llllll}
\hline & Number of respondents & Minimum & Maximum & Average & Standard deviation \\
\hline FCS & 160 & 21 & 71 & 37,06 & 7,43 \\
\hline
\end{tabular}

The average FCS of the surveyed farm households in Tokombéré commune is 37.06 with a minimum SCA of 21 and a maximum FCS of 71. This result is far from the average FCS calculated by the World Food Program [9] which was 40 for the Center Region of Cameroon and FCS calculated by Dibango [8] which was 46 in Mbalmayo. Households were divided into three different classes of FCS (poor, limited and acceptable consumption) according to the diversity and frequency of consumption of the different food groups. Figure 2 summarizes this distribution.

The food consumption score reflects food access and food consumption at the household level. The food consumption score can therefore be considered as a proxy indicator of the household food security situation. The following food safety classes have been established:

1. Households with poor food consumption are considered to be severely food insecure (SFI);

2. Households with limited food consumption are considered to be moderately food insecure (MFI);

3. Households with acceptable food consumption are considered food security (FS).

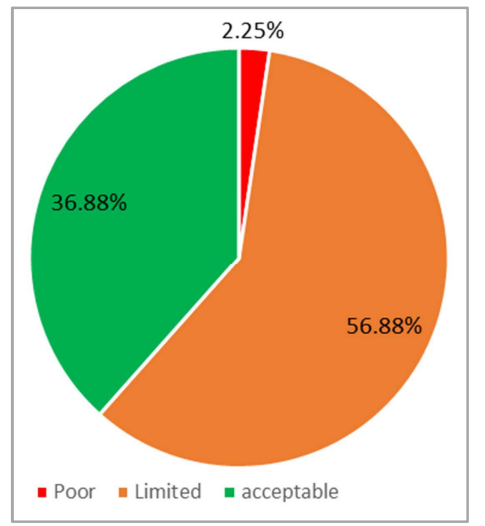

Figure 2. Distribution of surveyed households according to SCA classes.

For the purposes of the analysis, two classes were created: a class grouping households with severe food insecurity (SFI) and moderate food insecurity (MFS) and a second one concerning households in food security (FS).

It can be seen from Figure 2 that $36.88 \%$ of households have an acceptable diet (FCS $>38$ ), 56.88\% have a limited diet $(28 \leq \mathrm{FCS} \leq 38)$, and this result is close to that found by Soh Wenda [10] in the Bamboutos which was 55.41\%. And $6.25 \%$ have a poor diet. This proportion is the lowest, which is rather satisfactory. This is because land availability is not a limiting factor and all households have at least one parcel of land for agricultural practice. Also, the period of the surveys (beginning of the crop year) influenced these results, since this is the period when the availability of food is low in rural areas.

Class of households with poor food consumption: this class of consumption concerns $6.25 \%$ of the households surveyed (Figure 2). Households with this profile have a diet based primarily on the consumption of cereals accompanied by vegetables that are consumed daily. Access to animal protein and legumes is very low and is consumed at least once a week

Class of households with limited food consumption: this class of consumption concerns $56.88 \%$ of the households surveyed (Figure 2). Households with this profile have a diet based primarily on the consumption of cereals accompanied by vegetables that are consumed daily. Access to animal protein and legumes is very low and is consumed 1 or 3 times a week. The oil is an integral part of the diet and is consumed almost every 5 days. Dairy products are not consumed by this category at all. A balanced diet is not achieved because some households in this category are vulnerable and therefore run the risk of falling into the category of poor food consumption in case of shock.

Class of households with acceptable food consumption: this class represents almost four-fifths of the households surveyed (36.88\%) (Figure 2). Their diet is quite varied and the frequency of food consumption is higher. The diet is based on virtually all food groups. The cereals are the basic diet and are consumed every day sometimes accompanied (6 to 7 days / week) by animal protein in sauce. Legumes are consumed once a week and vegetables 2 to 7 days a week. The oil is consumed between 4 and 5 days in the week. Milk is poorly consumed (once a week).

\subsection{Evaluation of the Household Dietary Diversity Score (HDDS)}

The HDDS indicates the quality of food consumption, and to a lesser extent, the amount of food. It provides information on the number of different food groups consumed by the entire household during a given reference period (last 24 hours or last 7 days). But as part of this study, the reference period is 24 hours. The average HDDS of the agricultural producer households in Tokomberé commune is 3.58 with a minimum HDDS of 2 and a maximum HDDS of 9. The HDDS analyzes also show $75.6 \%, 20 \%$ and $4.4 \%$ of households which have the lowest, average and highest dietary diversity respectively. These results are far from those found by the World Food Program [11] in northern and eastern Côte d'Ivoire, where the proportion was more diversified (HDDS high) in the North $(86 \%)$ than in East $(52 \%)$.

\subsubsection{Distribution of the HDDS According to the Survey Villages}

The eating habits vary according to the geographical zones and the local productions. Their change over time is partly related to the different periods (harvest, transition and welding periods). The following table gives a breakdown of the SDAMs according to the villages surveyed. 
Table 3. Distribution of the HDDS according to the villages surveyed.

\begin{tabular}{|c|c|c|c|c|c|c|c|}
\hline \multirow[b]{2}{*}{ Food groups } & \multicolumn{6}{|c|}{ The household dietary diversity score (HDDS) } & \multirow[b]{2}{*}{ Total } \\
\hline & 2 & 3 & 4 & 5 & 6 & 9 & \\
\hline \multicolumn{8}{|l|}{ Villages } \\
\hline Bala Moraka & 1 & 12 & 3 & 4 & 0 & 0 & 20 \\
\hline Bzagamtagna & 2 & 9 & 5 & 4 & 0 & 0 & 20 \\
\hline Gozogol & 1 & 14 & 4 & 1 & 0 & 0 & 20 \\
\hline Kayamgali & 0 & 12 & 3 & 5 & 0 & 0 & 20 \\
\hline Serawa centre & 2 & 8 & 7 & 3 & 0 & 0 & 20 \\
\hline Dalazoulgo & 1 & 10 & 1 & 4 & 3 & 1 & 20 \\
\hline Moundouvaya & 0 & 10 & 9 & 1 & 0 & 0 & 20 \\
\hline Makaligaye centre & 3 & 7 & 9 & 1 & 0 & 0 & 20 \\
\hline Total & 10 & 82 & 41 & 23 & 3 & 1 & 160 \\
\hline
\end{tabular}

The table shows that during the survey period (May 2018), the proportion of households with a less diversified food consumption (low HDDS) is higher in Gozogol, BalaMouraka and Kayamgali villages than in the other villages. The highest HDDS was found in Dala-Zoulgo village with a proportion of one household out of the 20 respondents.

The most consumed food groups in people's eating habits are cereals, vegetables, oils. In the villages of the study area, the consumption of fruits, products from the picking, is seasonal.

\subsubsection{Distribution of HDDS According to Food Security Classes}

Low dietary diversity (consumption of less than 3 food groups) is higher in the severely food insecure classes. Figure 3 shows the distribution of HDDS according to food security classes. It shows respectively $90 \%$ and $79.12 \%$ of households with severe food insecurity and moderate food insecurity, respectively, who consume fewer than 3 food groups in

Figure 3 shows respectively $90 \%$ and $79.12 \%$ of households with severe food insecurity and moderate food insecurity, respectively, who consume fewer than 3 food groups in Tokombéré commune. These results revolve around those found by Agbo [12] in South-West Cote d'Ivoire

\subsection{Evaluation of Adaptation Strategies for Food (CSI-R)}

The CSI tracks changes in household behavior and indicates levels of food insecurity compared over time or from a baseline. The indicator provides information on the use (as well as the frequency) of behaviors or strategies (ie decreasing the amount of food at meals) during the last 7 days, if the household ran out of food or money to buy food [13]. It should be noted that the higher the CSI the more the household is food insecure and the lower the household, the less secure the household is compared to other households.

Table 4. Index of Adaptation Strategies for Food.

\begin{tabular}{llllll}
\hline & N & Minimum & Maximum & Moyenne & Standard deviation \\
\hline CSI & 160 & 11 & 30 & 21,10 & 5,95 \\
\hline
\end{tabular}

The average CSI of the agricultural producer households in Tokombéré commune is 21.1 with a minimum CSI of 11 and a maximum CSI of 30 . This result shows that households with below average CSI (21.1) are food secure only households that have a CSI above the average. In other words, households with a CSI of 11 are more food secure and households with a CSI of 30 are more food insecure relative to other households. Figure 4 provides a food security class correction for identified CSI

Tokombéré commune.

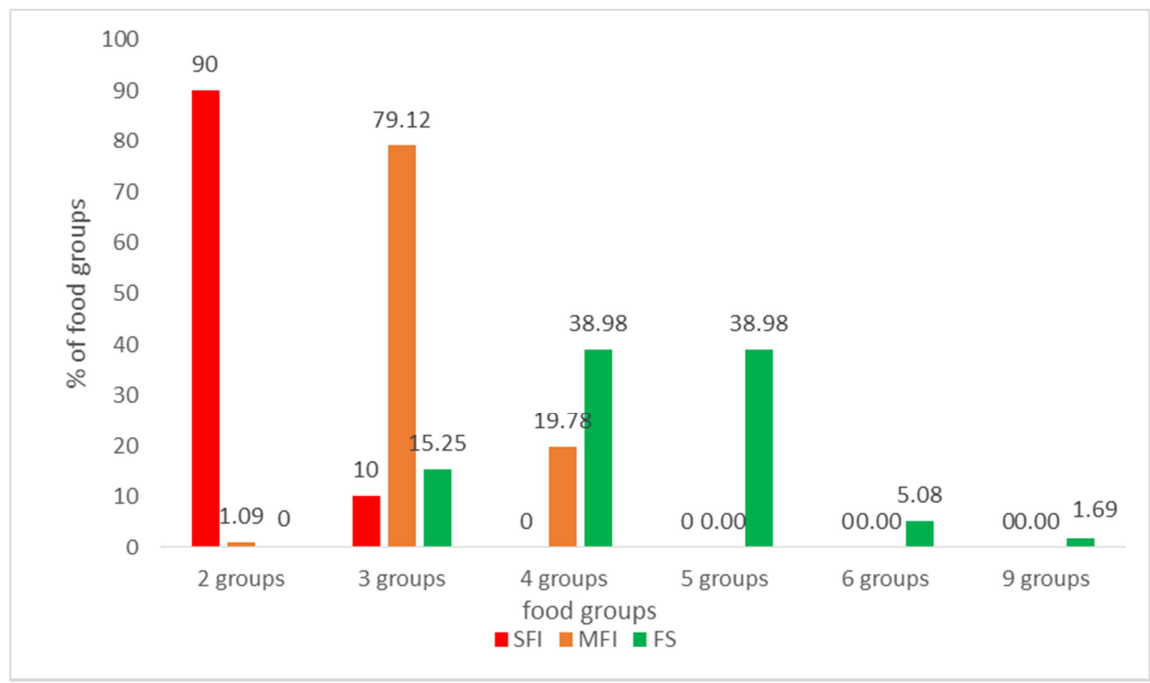

Figure 3. Distribution of HDDS according to food security classes. 


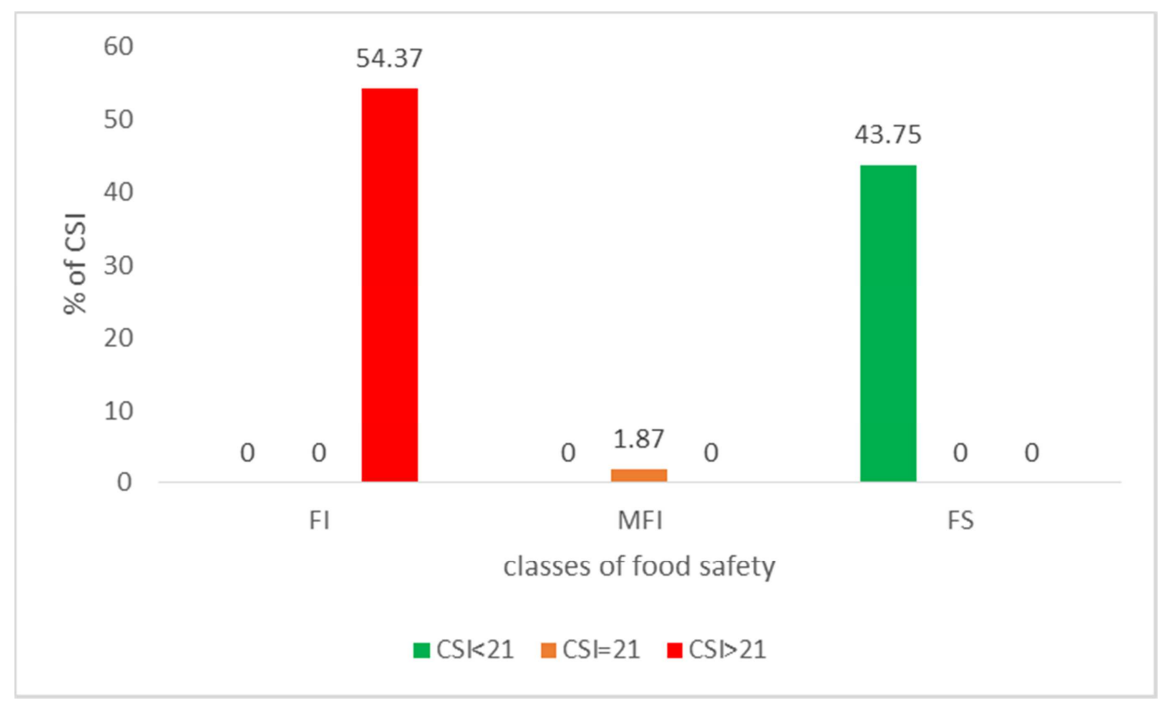

Figure 4. Distribution of CSI according to food security classes.

Figure 4 shows that with the CSI, $54.37 \%$ of households (or 87 households) are food insecure. In contrast, $43.75 \%$ of households (70 households) are in a situation of food security. And only $1.87 \%$ of households are moderately food insecure $(\mathrm{CSI}=$ Average $)$.

\section{Conclusion}

The objective of this study was to assess the food security of agricultural producers vulnerable to climate change in Tokombéré commune. For this purpose, three indicators were used to assess food security in order to achieve this objective: the Household Food Consumption Score (FCS), the Household Food Diversity Score (HDDS) and the Strategy Index adaptation for the food (CSI). The results showed with the FCS that $6.25 \%$ of households were severely food insecure, $56.88 \%$ were moderately food insecure and $36.88 \%$ were food secure. With the HDDS, it should be noted that the more the ration is diversified the more one is in food security and the less it is diversified the less one is in food security. For this, the results showed that those who are in SFI (90\%) and MFI (79.12\%) are those who consume less than 3 food groups since with the HDDS, we are food insecure when we consume less than 3 food groups. Similarly with the CSI, it was found that $54.37 \%$ of households are food insecure while $43.77 \%$ are food secure, only $1.87 \%$ are moderately food insecure. It is noted that with the three indicators of food security the proportion of households with food insecurity is the highest. This would be due to the poor production of producing households due to climatic hazards (pockets of drought). Climate change has a negative impact on the food security of these households. In addition, $80 \%$ of the surveyed households claimed to have bought the food they eat, which proves that their production does not allow them to cover their food needs throughout the year.

The worrying nature of the issue of climate change by linking with food insecurity, especially in developing countries, is an important factor in motivating further research in this area. The well-being of today's and future generations depends on it. It would be interesting to evaluate the sustainability of the strategies implemented in relation to the results of climate projections, to evaluate the feasibility of the measures (irrigation for example) aiming at the removal of agricultural activity from the climatic hazards.

\section{References}

[1] Deutsche GesellschaftFü Internationale Zusammenarbeit, (GIZ) 2013. Report of the study on the vulnerability of municipalities in the Far North region to the effects of climate change.

[2] Fourissala Robert H. et Gorno Jean, 2013 Climate change and migration in the Sahelian belt of Chad.Revista de historia, Juiz de Fora V18(02) 163-180.

[3] High Level Panel of Experts (HLPE), 2012. Food security and climate change. Report of the High Level Panel of Experts on Food Security and Nutrition of the Committee on World Food Security, Rome.

[4] United Nations (UN), 2017. Report of the Review Strategy for Food Security and Nutrition in Cameroon.

[5] Solidarités International (SI), 2015. Evaluation Report, Minawao Camp, Far North Cameroun .

[6] Morton John F., (2007) The impact of climate change on smallholder and subsistenc agriculture 104(50) 19680-19685.

[7] World Food Program (WFP), 2014. Rapid Assessment of Food Security for Central African Refugees and Host Populations in Eastern and Adamaoua Regions.

[8] DIBANGO Prisca M., (2016). Analysis of the Factors Influencing the Food Security of Cocoa Producing Households in the Mbalmayo Locality, Center Region (Engineering thesis). Faculty of Agronomy and Agricultural Sciences of the University of Dschang, Cameroon.

[9] World Food Program (WFP), (2007). Global Analysis of Food Security and Vulnerability (CFSVA) in Cameroon. Registered office: Via C. G. Viola 68, Parco de 'Medici, 00148, Rome, Italy. 
[10] Soh Wenda B. D., (2018) Integrating nutrition in agriculture extension services and its implications for rural household food security: Case of Bamboutos division, West region of Cameroon (Engineering thesis). Faculty of Agronomy and Agricultural Sciences of the University of Dschang, Cameroun.

[11] World Food Program (WFP), 2013. Final Report of the Survey of Food Insecurity and Vulnerability in West and North-West Côte d'Ivoire.
[12] Agbo, A. E., Kouame C., Kalhia J., Jiby L., Coulibaly L., Mahyao A. et Kehlenbeck K., (2015). Feeding habits and nutritionalstatus of youngchildren and theirmothers in cocoa producing smallholders households in South-West Cote d'Ivoire. Ibadan : ICRAF/IITA.

[13] Richard Caldwellet Daniel Maxwell, 2008. The CopingStrategies Index, A tool for rapidmeasurement of householdfoodsecurity and the impact of foodaid programs in humanitarian emergencies. 